C57BL/10 Idd5.1 locus and non-congenic NOD mice, which have haplotypes of the Idd5.1 region that confer protection against or susceptibility to T1D, respectively. The newly identified ligand-independent isoform of Ctla4 (liCtla4; a transmembrane isoform that lacks the CD80/CD86-binding domain) had a fourfold increase in expression by T cells from Idd5.1congenic mice compared with NOD mice.

So, these results indicate that differential expression of alternatively spliced forms of CTLA4 might have an important role in determining susceptibility to autoimmune disease. For example, the authors propose that reduced levels of sCTLA4 could increase T-cell activation by reducing binding of SCTLA4 to its ligands CD80/CD86 and allowing increased T-cell activation through CD28.

Kirsty Minton

(2) References and links Original ReSEARCh PAPER Ueda, H. et al. Association of the T-cell regulatory gene CTLA4 with susceptibility to autoimmune disease. Nature 30 April 2003 (DOI: 10.1038/nature01621)

FURTHER READING Sharpe, A. H. \& Freeman, G. J. The B7-CD28 superfamily. Nature Rev. Immunol. 2, 116-126 (2002)

lobes of the lung and is often asymptomatic. To reach the upper lobes, the most common site of pathology, movement through the bloodstream is required. As such, a vaccine that inhibits the process of dissemination from the site of primary infection would probably influence the course of disease.

The precise mechanisms that underlie the ability of the RD1 locus to enhance protection against $M$. tuberculosis remain to be elucidated. The presence of two extra antigens (ESAT6 and CFP10) that induce a more robust $\mathrm{CD} 4^{+} \mathrm{T}$-cell response, coupled with a possible role for these molecules in allowing the vaccine strain to persist in the host, might be important in contributing to the improved efficacy. Ultimately, the marked protection that is observed after re-incorporation of the RD1 locus indicates a compelling reason to include this modification in any recombinant BCG vaccine, and work is now underway to characterize other missing immunodominant antigens of M. tuberculosis that might improve the BCG vaccine even further.

David O'Connell, Editor, Nature Reviews Microbiology

(2) References and links

\section{ORIGINAL RESEARCH PAPER PYm, A. S. et al.}

Recombinant BCG exporting ESAT-6 confers enhanced

protection against tuberculosis. Nature Med. 14 April 2003 (DOI: 10.1038/nm859)

FURTHER READING Young, D. B. \& Stewart, G. R

Tuberculosis vaccines. Br. Med. Bull. 62, 73-86 (2002) Kaufmann, S. H. How can immunology contribute to the control of tuberculosis? Nature Rev. Immunol. 1, 20-30 (2001) WEB SITE

Pasteur Institute: http://www.pasteur.fr/english.html

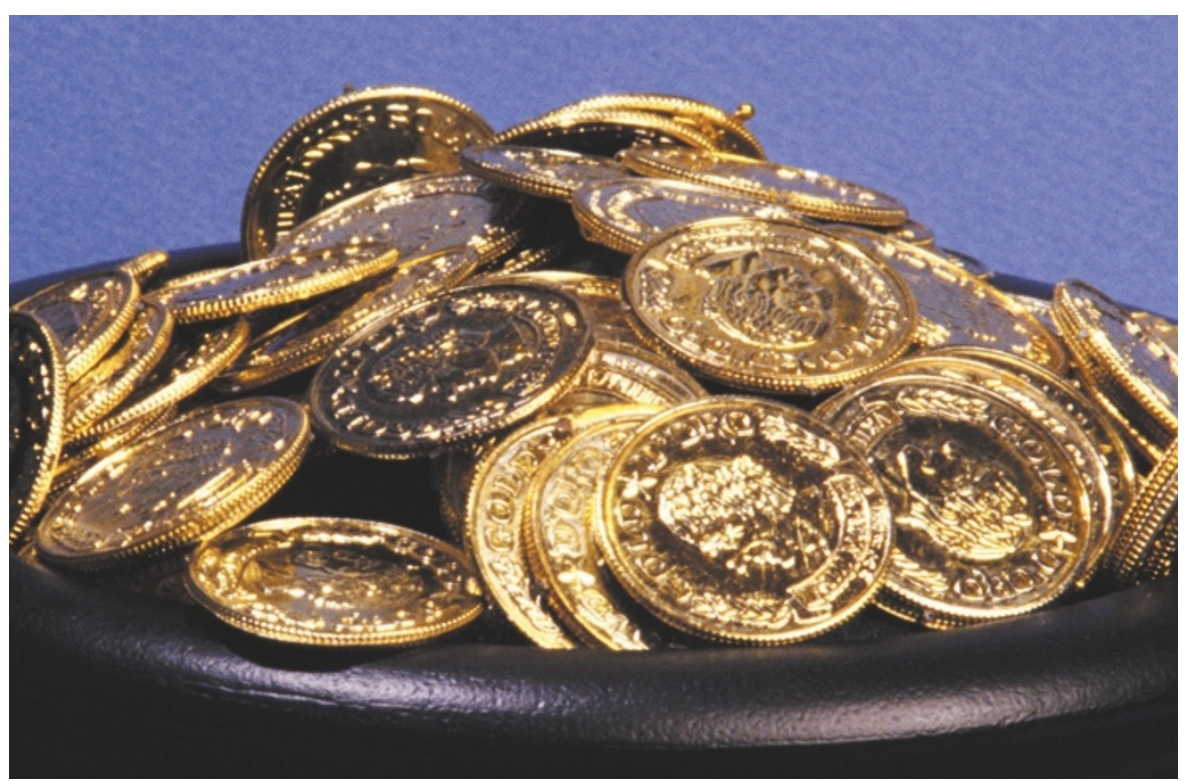

AUTOIMMUNITY

\title{
Autoimmunity and tolerance - two sides of the same coin
}

Induction of disease-specific tolerance using autoantigens is the goal of many ongoing studies of autoimmune disease. The potential application of this approach has now been shown in two related studies from Len Harrison's laboratory, but the potential pitfalls of this approach are apparent in the second study.

Steptoe and colleagues used non-obese diabetic (NOD) mice to test whether the expression of autoantigen by syngeneic haematopoietic stem cells (HSCs) can prevent the spontaneous development of diabetes by the induction of tolerance. The autoantigen proinsulin was targeted to resting antigenpresenting cells in NOD mice by expressing pro-insulin under the control of the MHC class II promoter (NOD-PI mice). When bone marrow from these mice was transferred to recipient wild-type NOD mice, the occurrence of insulitis was reduced, and the development of diabetes was prevented in most recipients. This also occurred in wild-type recipients of T-celldepleted bone marrow, indicating that transferred $\mathrm{T}$ cells did not contribute to the effect. Moreover, transfer of purified NOD-PI progenitor cells reduced the incidence of diabetes, and purified NOD-PI HSCs prevented diabetes in recipients. This study establishes proof of principle that syngeneic HSCs expressing autoantigens might be a useful therapeutic tool, but the precise mechanisms of tolerance induction require further study. The approach would require some modification for use in pre-diabetic humans and would also require vectors that can effectively transduce HSCs for long-term gene expression after engraftment.

In the second study, Martinez and colleagues tested whether autoantigenic peptides that were administered mucosally could inhibit the development of autoimmunity. Intranasal treatment of young NOD mice with the proinsulin peptide B24-C36 prevented them from developing diabetes, which is rapidly induced by injecting splenocytes from recently diabetic NOD mice, and this tolerogenic effect was due to the development of regulatory $\mathrm{CD} 4^{+} \mathrm{T}$ cells. Spontaneous diabetes in male NOD mice was reduced, but in females, development of diabetes indicated the simultaneous induction of cytotoxicity by mucosal administration of B24-C36. The authors found that this peptide contained overlapping $\mathrm{CD} 4^{+}$and $\mathrm{CD} 8^{+} \mathrm{T}$-cell epitopes. When the $\mathrm{CD} 8^{+} \mathrm{T}$-cell epitope was disabled by truncation of a binding anchor for $\mathrm{H}-2 \mathrm{~K}^{\mathrm{d}}$, a single intranasal administration of the truncated peptide was sufficient to prevent the development of diabetes in this system.

Together, these two studies show both sides of the coin of antigen-specific immunotherapy: the potential and the pitfalls.

(0) References and links

Elaine Bell

ORIGINAL RESEARCH PAPERS Steptoe, R. J. et al. Transfer of hematopoietic stem cells encoding autoantigen prevents autoimmune diabetes. J. Clin. Invest. 111, 1357-1363 (2003) | Martinz, N. R. et al. Disabling an integra Martinez, N. R. etal. Jis. Clin. suppression of autoimmune diabetes by intranasal proinsulin peptide. J. Clin. Invest. 111, 1365-1371 (2003) 